\title{
The prevalence and correlates of eating disorders in adult emergency department patients
}

\author{
Suzanne Dooley-Hash MD, FAED ${ }^{1,2}$ (1) | Mackenzie Adams BS ${ }^{3}$ | \\ Maureen A. Walton MPH, $\mathrm{PhD}^{4,5}$ | Frederic C. Blow $\mathrm{PhD}^{4}$ | \\ Rebecca M. Cunningham MD ${ }^{1,5}$
}

\author{
${ }^{1}$ Department of Emergency Medicine, \\ University of Michigan, Ann Arbor, Michigan \\ ${ }^{2}$ The Center for Eating Disorders, Ann Arbor, \\ Michigan \\ ${ }^{3}$ School of Public Health, University of \\ Michigan, Ann Arbor, Michigan \\ ${ }^{4}$ Department of Psychiatry, University of \\ Michigan, Ann Arbor, Michigan \\ ${ }^{5}$ Injury Prevention Center, University of \\ Michigan, Ann Arbor, Michigan

\section{Correspondence} \\ Suzanne Dooley-Hash, Department of \\ Emergency Medicine, University of Michigan, \\ Ann Arbor, MI. \\ Email: sldh@umich.edu \\ Funding information \\ National Institute on Alcohol Abuse and \\ Alcoholism, Grant/Award Number: 1 R01 \\ AA018659-01A1
}

\begin{abstract}
Objective: This study describes the prevalence of eating disorders among adult patients who present to the emergency department for medical care and examines the relationship between eating disorders, depression, and substance use disorders.

Method: Emergency department patients aged 21-65 years $(n=1,795)$ completed a computerized questionnaire that included validated screening tools for eating disorders, risky drinking behavior, other substance use, and depression. Analyses were conducted comparing individuals who screened positive for an eating disorder with those who did not based on demographics (gender, age, race, income, education), body mass index (BMI), risky drinking behavior, other substance use, and depression. Results: Nearly $16 \%$ (15.9\%) of all patients screened positive for an eating disorder regardless of their reason for presenting to the emergency department. Patients who screened positive for an eating disorder were significantly more likely to have a $\mathrm{BMI}>30$ (odds ratio $[\mathrm{OR}]=2.68$, confidence interval $[\mathrm{Cl}]=1.98,3.62, p<.001$ ), to also screen positive for depression $(\mathrm{OR}=3.19, \mathrm{Cl}=2.28,4.47, p<.001)$ and to be female $(\mathrm{OR}=2.37, \mathrm{Cl}=1.76,3.19, p<.001)$. No differences in the prevalence of positive screens for eating disorders were seen across age or racial groups, level of education or income, or for any of the included substance use variables.

Discussion: Eating disorders are common among adult emergency department patients and are associated with high rates of comorbid depression and higher BMI. Given the significant morbidity and mortality associated with eating disorders, targeted screening may be warranted in the emergency department setting.

\section{KEYWORDS}

comorbidity, eating disorders, emergency department, prevalence, screening
\end{abstract}

\section{1 | INTRODUCTION}

Eating disorders are serious mental illnesses that commonly have medical and psychiatric comorbidities. Mortality rates are increased in all eating disorders, with anorexia nervosa (AN) carrying among the highest of any mental illness (Arcelus, Mitchell, Wales, \& Neilson, 2011; Crow et al., 2009; Harris \& Barraclough, 1998). Studies in both the general population and primary care settings have shown that between 7 and $21 \%$ of individuals screen positive for an eating disorder (Johnston, Fornai, Cabrini, \& Kendrick, 2007; Mond et al., 2008). Individuals with eating disorders, whether diagnosed or undiagnosed, are also known to utilize all healthcare services, including emergency departments, more 
frequently than their peers (Dooley-Hash, Lipson, Walton, \& Cunningham, 2013; Ogg, Millar, Pusztai, \& Thom, 1997; Striegel-Moore et al., 2005). Additionally, one study found that the average number of emergency department visits correlates with greater severity of illness and higher mortality (Crow, Praus, \& Thuras, 1999).

The majority of individuals with eating disorders go unidentified, with estimates that only one-third will be diagnosed and receive treatment (Forrest, Smith, \& Swanson, 2017; Hart, Granillo, Jorm, \& Paxton, 2011). Even among those that are identified, there is often significant delay between onset of disorder and diagnosis (Le Grange \& Loeb, 2007). Adding to the urgency of identification is the increased favorability of recovery with early intervention (Deter \& Herzog, 1994; Ratnasuriya, Eisler, Szmukler, \& Russell, 1991; Treasure \& Russell, 2011). Given that the emergency department often acts as a "safety net" for individuals without insurance or access to primary care and that increased utilization of the emergency department has been observed among all mental illness diagnoses, including eating disorders (Dooley-Hash et al., 2013; Ogg et al., 1997; Striegel-Moore et al., 2005), visits to the emergency department may represent ideal opportunities to identify these disorders and to intervene. The variety and acuity of illness seen in fast-paced emergency departments coupled with the lack of personnel qualified to perform a diagnostic evaluation preclude definitive diagnosis of an eating disorder in this setting. However, utilization of a brief screening tool to identify those who warrant referral for further diagnostic evaluation may be feasible. Individuals who screen positive could be provided resources and referred to appropriate outpatient providers.

Although there is no literature pertaining to such protocols for eating disorders, there is significant research demonstrating benefits of emergency department screening and intervention programs for other mental illnesses. For instance, multiple studies of Screening, Brief Intervention and Referral to Treatment (SBIRT) programs for alcohol use have shown that these programs can significantly decrease amount of alcohol consumed and risky drinking behaviors (Barata et al., 2017; Cunningham et al., 2015). A 2018 study of SBIRT for alcohol use also found improved patient outcomes and decreased subsequent healthcare utilization with a $21 \%$ decrease in healthcare costs (Pringle et al., 2018). One study of screening for alcohol use that included referral to appropriate treatment without further intervention in the emergency department found significant reductions in drinks/week in the $65.8 \%$ of participants that followed through with the referrals (Crawford et al., 2004). Similarly, an emergency department program involving screening for suicide risk accompanied by a brief intervention that included developing a safety plan and/or a follow-up call after discharge decreased subsequent suicide attempts over the following 52 weeks (Miller et al., 2017).

Finally, while there have been numerous studies establishing the prevalence of eating disorders in other medical care settings, universities, and the general population, to the best of our knowledge, the only other study of screening for eating disorders among the emergency department patients was limited to individuals aged 14-20 years old (Dooley-Hash, Banker, Walton, Ginsburg, \& Cunningham, 2012). The primary goal of this study is to establish the prevalence of eating disorders in adult emergency department patients $\geq 21$ years. This information may be used to inform future studies on the feasibility and utility of screening for eating disorders in emergency departments. Increasing awareness of these potentially deadly disorders among healthcare professionals by demonstrating their prevalence is an important secondary goal. We hypothesize that the prevalence in this study will be similar to or higher than that previously found in the general population and primary care settings.

\section{2 | METHOD}

\section{1 | Study design and setting}

Data for this study were collected as part of a larger randomized controlled trial in which patients were screened for risky drinking and other health behaviors (Project Health Explorer; Fernandez et al., 2019). Study participants were recruited to complete a screening survey in Adult Emergency Services (AES) of a large university-based hospital, Michigan Medicine, in Ann Arbor, Michigan. Approval of study protocol was obtained from the University of Michigan's Institutional Review Board prior to the start of the study. A Certificate of Confidentiality for human participants was obtained through the National Institutes of Health.

Patients aged 21-65 years presenting to the emergency department for medical care were screened for eligibility and recruited for the study from February 2012 through August 2012. Exclusion criteria included acute psychiatric condition (e.g., suicidal ideation or attempt, psychoses), medical instability, those who could not give consent (altered mental status, limitations in language, literacy or cognitive skills), and prior participation.

All study-eligible patients were identified through electronic patient tracking logs. They were approached by research assistants (RAs) in treatment areas, provided written informed consent and self-administered a 15-min. computerized screening survey. All information gathered was self-reported by the patients and no protected health information was collected from hospital records. For participation, patients received a gift valued at $\$ 1.00$ (e.g., puzzle book, playing cards, travel mug, pens). Gender was recorded for those who declined to participate.

\section{2 | Study measures}

\subsection{1 | Demographics}

Demographic information collected included gender, age, race, level of education and income. Level of education was measured on a 6-item scale with 1 = less than eighth grade, 2 = some high school, 3 = high school graduate or Graduate Record Exam (GRE), 4 = some college, 5 = college graduate and $6=$ postgraduate level. Income was measured on a 7 -item scale with $1=$ less than $\$ 10,000$ /year through $7=$ greater than $\$ 100,000 /$ year.

\subsection{2 | Body mass index}

Body mass index (BMI) was calculated from self-reported height and weight $\left(\mathrm{BMI}=\right.$ weight in pounds $\left./[\text { height in inches }]^{2}\right)$. Patients were 
categorized based on BMI as defined by the World Health Organization (1995).

\subsection{3 | Eating disorders}

A modified version of the SCOFF was used to screen for the presence of eating disorders. The SCOFF is a previously validated, self-report questionnaire that consists of five yes/no questions. It was originally designed to assess the core features of $\mathrm{AN}$ and bulimia nervosa (Morgan, Reid, \& Lacey, 1999). Two or more "yes" answers on the SCOFF are considered a positive screen and identify a possible eating disorder. The SCOFF is not a diagnostic tool and cannot differentiate between the eating disorders. The cutoff score of $\geq 2$ positive answers has been validated in multiple prior studies with sensitivity between 72 and $100 \%$ and specificity between 73 and 94\% (Cotton, Ball, \& Robinson, 2003; Hill, Reid, Morgan, \& Lacey, 2010; Luck et al., 2002; Mond et al., 2008; Morgan et al., 1999). For this study, we used the mSCOFF (Figure 1) which contains minor modifications from the original. These modifications include wording changes to reflect linguistic differences between the United States and the United Kingdom (i.e., "stone" changed to "pounds") and the addition of "or gained" to question 3. The latter change is intended to capture disorders that may involve rapid weight gain, rather than loss, such as binge-eating disorder (BED) and other forms of eating disorders (Dooley-Hash et al., 2012). A cutoff score of $\geq 2$ positive answers on the mSCOFF is also considered positive for an eating disorder.

\subsection{4 | Depression}

The abbreviated Patient Health Questionnaire (PHQ-8) was used to screen for major depression. The PHQ-8 consists of the first eight questions of the original nine-item PHQ (Spitzer, Kroenke, \& Williams,
1999). A cutoff score of $\geq 4$ on the PHQ-8 has previously been shown to be effective in screening for major depression (73\% sensitivity, $94 \%$ specificity) and was used in this study's analyses (Spitzer et al., 1999).

\subsection{5 | Alcohol use}

The Alcohol Use Disorders Identification Test (AUDIT)-C was used to assess for risky drinking behavior in the previous 3 months. The AUDIT$C$ consists of the first three questions (consumption items) of the full 10-item AUDIT. Cutoff scores of 4 for men and 3 for women have previously been established and are both sensitive (82.6-86\%) and specific (72-82.6\%) for identifying alcohol use disorders and risky drinking behavior (Bush, Kivlahan, McDonell, Fihn, \& Bradley, 1998; Choo, McGregor, Mello, \& Baird, 2013; Dawson, Smith, Saha, Rubinsky, \& Grant, 2012). For the purposes of analyses in this study, an AUDIT-C score $\geq 3$ for women or $\geq 4$ for men was considered positive for risky drinking behavior.

\subsection{6 | Substance use}

Screening for use of tobacco and/or any drugs including over-the-counter, illicit, and nonmedical prescription drug use during the previous 3 months was accomplished using questions taken from the Alcohol, Smoking, and Substance Involvement Screening Test, which has demonstrated $91-94 \%$ sensitivity and $87-94 \%$ specificity for use of the substances included (WHO ASSIST Working Group, 2002). For analyses, variables were dichotomously coded (no use/any use). Categories of drugs were defined as: tobacco, cannabis, stimulants (methamphetamine, cocaine, and prescription stimulants), and other drugs (inhalants, hallucinogens, illicit and prescription opioids, dextromethorphan, and sedatives).

Please read the questions below and check the appropriate answer box below. This information will be kept confidential and will not be shared with anyone except the researchers conducting this study.

1) Do you ever make yourself throw up (or use laxatives, water pills or exercise) because you feel uncomfortably full?

$\square$ Yes $\quad \square$ No

2) Do you worry you have lost control over how much you eat?

$\square$ Yes $\quad \square$ No

3) Have you recently lost or gained more than 15 pounds in a 3 month period?

$\square$ Yes $\quad \square$ No

4) Do you believe yourself to be fat when others say you are too thin?

$\square$ Yes $\quad \square$ No

FIGURE 1 Modified SCOFF questionnaire
5) Do thoughts about food and weight dominate your life? 


\section{3 | Statistical analysis}

Bivariate analysis was utilized to compare patients who screened positive for an eating disorder with those who screened negative. The chi-squared test (for categorical variables) and $t$ test (for continuous variables) were used to determine statistical significance. Multinomial logistic regression was used to adjust for the effect of each variable on the others in order to identify variables independently associated with screening positive for an eating disorder. Odds ratios (ORs) and $95 \%$ confidence intervals ( $\mathrm{Cls}$ ) are reported. The Hosmer-Lemeshow test was used to assess the fit of the final model (Hosmer \& Lemeshow, 2000). Data were analyzed in SPSS version 24 (IBM Corporation, 2016).

\section{3 | RESULTS}

A total of 4,651 patients were selected by RAs for possible inclusion in the study. Of these, 3,273 (70.3\%) patients were eligible for screening. The majority of exclusions were due to altered cognition, (43.7\%) and medical instability (17.0\%; Table 4). Of eligible patients, 2,326 (71.1\%) were approached for screening whereas 947 (28.9\%) were missed due to circumstances such as the patient being unavailable during testing or physician evaluation, multiple eligible patients present, and patients not being identified. Among the patients approached, 530 (22.8\%) declined to participate whereas 1,795 (77.2\%) agreed. Participants were more likely to be female (62.8\%) as were those who declined (61.5\%) with no statistical difference in rates of participation related to gender $(p=.56)$. The average age of participants was 40.7 years (SD 13.0) and the majority were White (79.4\%). Participants' reported average annual household income had a mean of 4.0/7 scale representing an income of between $\$ 40,000$ and $\$ 60,000$ USD (United States Dollar). The average level of education was reported as $4.3 / 6$, which correlates to some college education. As indicated by a positive mSCOFF, $15.9 \%$ of patients screened positive for an eating disorder. BMI as calculated from self-reported height and weight was $<18.5$ in $2.9 \%$ of patients, $18.5-24.99$ in $30.8 \%$, $25-29.99$ in $28.6 \%$, and $\geq 30$ in $37.7 \%$ (Table 1 ).

Bivariate analysis of baseline characteristics showed that patients who screened positive for an eating disorder were more likely to be female than male $(9.4 \%$ vs. $19.8, O R=2.37$, confidence interval $[\mathrm{Cl}]=1.76,3.19, p<.001)$. Average BMI was higher in patients with positive screens for eating disorders $(32.9$ vs. $28.5, \mathrm{OR}=1.06$, $\mathrm{Cl}=1.05,1.08, p<.001$ ) who were also more likely to have $\mathrm{BMI}>30$ (OR $=2.66, \mathrm{Cl}=2.05,3.44, p<.001)$. These individuals were also more likely to screen positive for depression $(\mathrm{OR}=3.84, \mathrm{Cl}=2.87$, $5.15, p<.001)$. Average income was lower in patients with positive screens for eating disorders $(\mathrm{OR}=0.85, \mathrm{Cl}=0.79,0.91, p<.001)$ who were more likely to have an annual income $<\$ 40,000$ (OR $=1.83$, $\mathrm{Cl}=1.38,2.42, p<.001)$. No significant difference in age was found when analyzed by average (39.1\% [SD 3.0] vs. $41.0 \%$ (13.1), OR = 0.99, $\mathrm{Cl}=0.98,1.00, p=.025)$ or by decade of life. Differences were not found across racial groups, level of education, or for any of the included substance abuse variables (Table 2).
TAB LE 1 Demographics and prevalence of eating disorders among emergency department patients $(n=1,795)$

\begin{tabular}{|c|c|c|}
\hline & $N$ & $\%$ \\
\hline Age-mean (SD) & $40.7(13.0)$ & - \\
\hline Female & 1,127 & 62.8 \\
\hline Male & 668 & 37.2 \\
\hline White & 1,426 & 79.4 \\
\hline African American & 312 & 17.4 \\
\hline Indian & 79 & 4.4 \\
\hline Asian & 48 & 2.7 \\
\hline Pacific islander & 6 & 0.3 \\
\hline BMI-mean (SD) & $29.2(8.0)$ & - \\
\hline$<18.5$ & 52 & 2.9 \\
\hline $18.5-24.99$ & 552 & 30.8 \\
\hline $25-29.99$ & 514 & 28.6 \\
\hline$\geq 30$ & 677 & 37.7 \\
\hline Eating disorder positive (SCOFF $\geq 2$ ) & 286 & 15.9 \\
\hline Income (in USD)-mean (SD) & $4.0(2.1)$ & - \\
\hline $1=<\$ 10,000$ & 242 & 13.5 \\
\hline $2=\$ 10,000-19,999$ & 192 & 10.7 \\
\hline $3=\$ 20,000-39,999$ & 289 & 16.1 \\
\hline $4=\$ 40,000-59,999$ & 204 & 11.4 \\
\hline $5=\$ 60,000-79,999$ & 174 & 9.7 \\
\hline $6=\$ 80,000-99,999$ & 11 & 6.3 \\
\hline $7=>\$ 100,000$ & 331 & 18.4 \\
\hline Missing or do not know & 250 & 14.0 \\
\hline Education-mean (SD) & $4.3(1.1)$ & - \\
\hline $1=<8$ th grade & 13 & 0.7 \\
\hline $2=$ Some high school & 78 & 4.3 \\
\hline $3=$ High school graduate or equivalent & 327 & 18.2 \\
\hline $4=$ Some college & 629 & 35.0 \\
\hline $5=$ College graduate & 449 & 25.0 \\
\hline $6=$ Graduate degree & 299 & 16.7 \\
\hline
\end{tabular}

Abbreviation: SD, standard deviation.

Multinomial analyses showed that even when adjusting for each of the independent variables, gender, BMI, and depression remained significantly related to screening positive for an eating disorder while income did not (Table 3). Patients with positive screens were more likely to be female (OR $=2.48, \mathrm{Cl}=1.73,3.54, p<.001)$, have $\mathrm{BMI}>30(\mathrm{OR}=2.68, \mathrm{Cl}=1.98,3.62, p<.001)$, and/or also screen positive for depression ( $\mathrm{OR}=3.19, \mathrm{Cl}=2.28,4.47, p<.001)$ than those who screened negative for eating disorders. The association between eating disorders and income was not significant in the multivariate analysis $(\mathrm{OR}=0.90, \mathrm{Cl}=0.83,0.98, p=.019)$.

\section{DISCUSSION}

To the best of our knowledge, this study is the first to examine the prevalence of eating disorders among emergency department patients 
TAB LE 2 Comparison of baseline characteristics, alcohol, and drug use and depression between patients who screen positive versus negative for eating disorder ( $n=1,795$; bivariate analysis)

\begin{tabular}{|c|c|c|c|c|}
\hline & SCOFF $+n=286(15.9 \%)$ & SCOFF $-n=1,509$ (84.1\%) & Odds ratio $(95 \% \mathrm{Cl})$ & $p$ value \\
\hline Age-mean (SD) & $39.1(13.0)$ & $41.0(13.1)$ & $0.99(0.98,1.00)$ & .025 \\
\hline $21-29$ years & $90(16.4)$ & $459(83.6)$ & $1.42(1.08,1.87)$ & .01 \\
\hline $40-49$ years & $60(15.3)$ & $332(84.7)$ & $0.94(0.69,1.28)$ & .38 \\
\hline $50-59$ years & $56(14.4)$ & $361(86.6)$ & $0.96(0.70,1.32)$ & .44 \\
\hline Female & $223(19.8)$ & $904(80.2)$ & $2.37(1.76,3.19)$ & $<.001$ \\
\hline Male & $63(9.4)$ & $605(90.6)$ & - & - \\
\hline White & $228(79.7)$ & $1,198(79.4)$ & $1.02(0.75,1.40)$ & .90 \\
\hline BMI-mean (SD) & $32.9(9.6)$ & $28.5(7.4)$ & $1.06(1.05,1.08)$ & $<.001$ \\
\hline$<18.5$ & $6(11.5)$ & $46(11.5)$ & $0.73(0.31,1.69)$ & .29 \\
\hline $\begin{array}{l}\text { Risky drinking (AUDIT-C } \geq 3 \text { for } \\
\text { women, } \geq 4 \text { for men) }\end{array}$ & $57(19.9)$ & $337(22.3)$ & $0.87(0.63,1.19)$ & .37 \\
\hline Tobacco use & $105(18.0)$ & $479(82.0)$ & $1.25(0.96,1.62)$ & .10 \\
\hline Marijuana use & $63(21.1)$ & $236(78.9)$ & $1.52(1.12,2.08)$ & .01 \\
\hline Stimulant use & $15(25.4)$ & $44(74.6)$ & $1.84(1.01,3.36)$ & .05 \\
\hline Other drug use & 75 (20.3) & $294(79.7)$ & $1.47(1.10,1.97)$ & .010 \\
\hline PHQ-8-positive (>4) & $220(22.9)$ & 701 (76.1) & $3.84(2.87,5.15)$ & $<.001$ \\
\hline
\end{tabular}

Abbreviation: $\mathrm{Cl}$, confidence interval.

TAB LE 3 Comparison of levels of income and education between patients who screen positive versus negative for eating disorder $(n=1,795$; bivariate analysis)

\begin{tabular}{|c|c|c|c|c|}
\hline & SCOFF $+n=286(15.9 \%)$ & SCOFF $-n=1,509$ (84.1\%) & Odds ratio $(95 \% \mathrm{Cl})$ & $p$ value \\
\hline Income ${ }^{a}-$ mean (SD) & $3.4(1.9)$ & $4.1(2.1)$ & $0.85(0.79,0.91)$ & $<.001$ \\
\hline $1=<\$ 10,000$ & $46(19.0)$ & $196(81.0)$ & $1.35(0.95,1.93)$ & .06 \\
\hline $3=\$ 20,000-39,999$ & $54(18.7)$ & $235(81.3)$ & $1.33(0.95,1.86)$ & .06 \\
\hline $4=\$ 40,000-59,999$ & $38(18.6)$ & $166(81.4)$ & $1.30(0.89,1.90)$ & .11 \\
\hline $6=\$ 80,000-99,999$ & $16(14.2)$ & $97(85.8)$ & $0.90(0.87,0.94)$ & .40 \\
\hline $7=>\$ 100,000$ & $28(8.5)$ & $303(91.5)$ & $0.44(0.29,0.67)$ & $<.001$ \\
\hline Education-mean (SD) & $4.2(1.1)$ & $4.3(1.1)$ & $0.90(0.80,1.00)$ & .05 \\
\hline $1=<8$ th grade & $3(23.1)$ & $10(76.9)$ & $1.59(0.44,5.81)$ & .34 \\
\hline $2=$ Some high school & $11(14.1)$ & $67(85.9)$ & $0.86(0.45,1.65)$ & .39 \\
\hline $6=$ Graduate degree & $39(13.0)$ & $260(87.0)$ & $0.76(0.53,1.09)$ & .77 \\
\hline
\end{tabular}

Abbreviation: $\mathrm{Cl}$, confidence interval.

${ }^{\mathrm{a}}$ Two hundred and fifty missing values for income, $n=1,545$.

$\geq 21$ years. As predicted, our observed prevalence (15.9\%) was consistent with that found in multiple prior screening studies in other healthcare settings (7-21\%; Hill et al., 2010; Johnston et al., 2007;
Mond et al., 2008). Since the emergency department may be used in lieu of primary care and may represent the only source of healthcare for some patients, similar prevalence between these settings is not 
(Dooley-Hash et al., 2013; Ogg et al., 1997; Striegel-Moore et al., 2005).

Interpretation of the prevalence of positive screens for eating disorders reported in this study should also take into consideration that participants were recruited in Adult Emergency Services, which is separate from Psychiatric Emergency Services (PES) in our institution. Individuals with primary psychiatric complaints such as anxiety, depression, and suicidal ideation are normally evaluated in PES. These individuals would not typically be treated in AES unless they have a significant coexisting need for medical care due to conditions such as intoxication, self-harm requiring intervention, or overdose. Given that, individuals with eating disorders frequently have comorbid psychiatric conditions it is possible that many were evaluated in PES rather than AES and would, therefore, not be represented in this study. In this case, it is possible that our reported prevalence may actually be a significant underestimation.

When comparing baseline characteristics of study participants, there are several interesting findings. First is the consistent prevalence of positive screens for eating disorders throughout the lifespan. Indeed, there was no significant difference found at any age (Table 1). In addition, this study's reported prevalence is nearly identical to that reported in one previous study of adolescent and young adult emergency department patients (16\%; Dooley-Hash et al., 2012). This finding adds to the growing body of literature that describe higher than previously reported prevalence of eating disorders in midlife and beyond (Brandsma, 2007; Gagne et al., 2012, Maine, Samuels \& Tantillo, 2015; MangwethMatzek, Hoek, \& Pope Jr, 2014; Mangweth-Matzek, Hoek, Rupp et al., 2014; Micali et al., 2017; Swanson, Crow, Le Grange, Swendsen, \& Merikangas, 2011). The average age of study participants was, however, noted to be considerably higher than that of the local population (40.7, SD 13.0 vs. 33.4 years; United States Census Bureau [USCB]-a, 2018). This is reflective of the higher average age of emergency department patient populations due to increasing use of healthcare by older individuals as they develop more medical conditions with age. It is also possible that individuals who chose to participate in this study were older than those who refused.

The majority of study participants were women (62.8\%), which is a higher proportion than expected. Interestingly, $61.5 \%$ of those who declined to participate were also female indicating that the gender ratio between the two groups is representative of the study eligible patient population. The general emergency department population during the time of the study was $53.7 \%$ female versus $46.3 \%$ male, however. This suggests that men were more likely to be excluded from participation, possibly for reasons such as medical instability and/or altered cognition. Further information is not available on the excluded patients and the impact of gender differences in eligibility on the study findings is unclear.

Although men screened positive significantly less often than women ( $9.4 \%$ vs. $19.8 \%$ ), they accounted for $23 \%$ of all positive screens which is considerably higher than previous estimates (<10\%; Weltzin et al., 2012). It is unclear if this increased prevalence reflects a true change in the prevalence of eating disorders in men, an increased willingness by men to report disordered 
eating behaviors or an artifact of the emergency department patient population.

Additionally, we found no statistically significant differences related to racial groups or income. This is consistent with recent studies that suggest an increase in prevalence among different racial or socioeconomic (SES) groups (Dooley-Hash et al., 2012; Pike, Dunne, \& Addai, 2013; Pike, Hoek, \& Dunne, 2014). The demographic make-up of our study population, however, makes these results somewhat difficult to interpret. Whites represented $79.4 \%$ of participants which is consistent with $74.8 \%$ in the local population (USCB-a, 2018), but obviously lacks significant diversity. The low numbers of individuals from different racial groups may limit the power of our study to identify significant differences related to race.

Regarding SES, no significant difference in income between screen positive versus negative participants was found when other variables were adjusted for, but the average annual household income among study participants $(\$ 40,000-\$ 60,000$ USD) was considerably lower than that of the surrounding area at that time $(\$ 68,472$ USD; USCB-b, 2018). This difference suggests that the emergency department population is not fully representative of the local community. Potential explanations include that the study hospital location situated between two large public universities where many students have limited income. Also, many patients who present to the emergency department for care may do so because of limited resources and access to healthcare elsewhere.

No differences were found in level of education, which, on average, included at least some college education. This is consistent with the local community where $95.1 \%$ of adults have graduated from high school and more than half have a bachelor's degree or higher (United States Census Bureau-c, 2018).

As predicted, our results indicate an association between eating disorders and depression which is consistent with the established comorbidity between these disorders (Castillo \& Weiselberg, 2017; Guerdjikova, Mori, Casuto, \& McElroy, 2017; Moskowitz \& Weiselberg, 2017). Although it is not possible or appropriate to attempt to definitively diagnose and treat depression or eating disorders in an emergency department setting, performing a brief screening for either may be feasible. Individuals who screen positive could be provided resources and then referred to appropriate outpatient providers. As mentioned earlier, prior studies have found that such programs involving emergency department screening and referral/intervention for other mental illnesses have been successful in reducing subsequent illness-related symptoms and behaviors (Crawford et al., 2004; Miller et al., 2017). These findings suggest that there may be benefit to the development and use of similar programs for other illnesses including eating disorders. The relatively high prevalence of positive screens for eating disorders found in our study along with the significant medical and psychiatric risks of these disorders suggests that further work to develop and evaluate such programs may be warranted.

Surprisingly, our results did not indicate significant differences in prevalence of substance use disorders between those who did and did not screen positive for an eating disorder. The observed rates of associations (2.9-31.7\%) are, however, consistent with those seen in prior studies (Fouladi et al, 2015, Hudson et al., 2007; Killeen et al.,
2011; Krug et al., 2008). The study exclusion of individuals who were acutely intoxicated, some of whom may have a substance use disorder, precludes accurate characterization of the relationship between eating disorders and substance use disorders and is a limitation of this study.

Lastly, individuals who screened positive for eating disorders in this study had significantly higher BMI than those who screened negative. This is consistent with previous findings (Hudson et al., 2007) and also with the true distribution of weight in eating disorders. Only individuals with the least common eating disorder, AN, have lower weights while the majority of those with eating disorders have normal to higher weights. It is notable that those screening positive were more likely to have a BMI > 30. It is unclear if this is related to the distribution of types of eating disorders, that people with higher weights were more likely to present to the emergency department, or if this is just an artifact of the patient population. Regardless, the BMI finding represents an opportunity to dispel a common myth about low weight and eating disorders among healthcare professionals (HCPs). Even though the true weight distribution in eating disorders is well known to eating disorder treatment professionals, most other HCPs have very little understanding of this and many other important aspects of eating disorders. Multiple studies have demonstrated a lack of knowledge about and understanding of eating disorders among multidisciplinary HCPs including physicians, nurses, dietitians and others (Anderson, Accurso, Kinasz \& Le Grange, 2015; Ayton \& Ibrahim, 2018, Seah, Tham, Kamaruzaman, \& Yobas, 2017). One recent review showed that HCPs feel their knowledge about eating disorders is poor and demonstrate low confidence in their ability to identify and/or care for individuals with eating disorders. Another study found that HCPs believed that eating disorders are rare and unlikely to be encountered in many healthcare settings (Anderson, Accurso, Kinasz, \& Le Grange, 2017). Misunderstandings about eating disorders are understandable in light of the fact that some medical trainees receive no education on eating disorders and many receive at most $<2-4 \mathrm{hr}$ throughout their training (Ayton \& Ibrahim, 2018; Seah et al., 2017). Studies such as the current one are one way to make more up-to-date and accurate knowledge available to HCPs in efforts to address these critical knowledge gaps and improve early identification of those with these serious disorders.

\section{1 | Limitations}

In addition to potential limitations included in the discussion above, this study does have others worth mentioning. First, this study was conducted at a single large, academic tertiary care center. Findings may not generalize to other emergency department settings.

Since information on reasons for presentation to the emergency department is not available, we should also consider the possibility that some study participants had previously been diagnosed with an eating disorder and were already receiving adequate treatment. In this case, emergency department screening would not add value to their care and valuable resources may be wasted. However, given that the majority of individuals with eating disorders go undiagnosed and most 
do not receive appropriate treatment for their disorder, it seems unlikely that a large number of participants in this study would already be identified and receiving adequate care.

Also, since detailed information is not available about individuals who declined to participate in this study, it is unclear how representative our sample actually is of the general emergency department patient population. It is possible that some of the individuals who were approached for participation in the study had previous experience or interest in one of the screening components and were, therefore, more or less likely to participate. This potentially introduces selection bias and could impact study results. Although this is certainly feasible, it seems less likely that the presence or absence of an eating disorder itself directly influenced individuals' decisions to participate in a significant way given that the five questions of the SCOFF were embedded within a questionnaire that included more than 100 questions covering many topics. The study was explained to participants as a survey on health risk behaviors and eating disorders were not mentioned in the introduction.

Finally, it is unclear to what extent that the study exclusion criteria impacted our results. For instance, $3.9 \%$ of excluded patients had acute suicidal or homicidal ideation, $7.1 \%$ were intoxicated and $17.0 \%$ were medically unstable (Table 4). With the known comorbidity between eating disorders and substance use, suicide risk, and medical complications, it is possible that many of these patients may have screened positive for an eating disorder. This raises the possibility that our results might actually underestimate the true prevalence of eating disorders. Conversely, it is also possible, although unlikely, that none of the excluded patients would have screened positive, which would negatively impact the observed prevalence.

\section{5 | CONCLUSION}

Eating disorders are a significant source of morbidity and mortality. This pilot study of screening for eating disorders in the emergency department adds to the growing body of evidence demonstrating that eating disorders occur in a much more diverse population than previously thought, including in men, older individuals and racial minority groups. The study also demonstrates that many people who potentially have an eating disorder present to the emergency department for care. Although this setting is not appropriate for full evaluation or treatment of individuals with eating disorders, emergency department visits may represent excellent opportunities to screen for these potentially fatal disorders and to provide appropriate referral and resources.

Although there are limitations to our study, it does give a first look at the prevalence of eating disorders in emergency departments and lays the groundwork for additional studies in this area. Future studies utilizing multiple sites with more diverse populations would improve generalizability and power to find any differences between races. Including additional information on the patients who were excluded from the study might also help answer questions about the study population being truly representative. Follow-up studies that include further diagnostic evaluation of individuals who screened positive would help to determine the true prevalence and the sensitivity and specificity of the SCOFF in this setting. Finally, additional studies of screening and possibly referral or intervention programs for eating disorders in emergency departments are needed to further evaluate the feasibility and utility of these programs in this setting.

\section{ORCID}

Suzanne Dooley-Hash (DD https://orcid.org/0000-0003-0510-5736

\section{REFERENCES}

American Psychiatric Association. (2013). Diagnostic and statistical manual of mental disorders (5th ed.). Arlington, VA: American Psychiatric Publishing, Inc.

Anderson, K., Accurso, E., Kinasz, K., \& Le Grange, D. (2017). Residents' and Fellows' knowledge and attitudes about eating disorders at an Academic Medical Center. Academic Psychiatry, 41(3), 381-384.

Arcelus, J., Mitchell, A., Wales, J., \& Neilson, S. (2011). Mortality rates in patients with anorexia nervosa and other eating disorders. A metaanalysis of 36 studies. Archives of General Psychiatry, 68(7), 724-731.

Ayton, A., \& Ibrahim, A. (2018). Does UK medical education provide doctors with sufficient skills and knowledge to manage patients with eating disorders safely? Postgraduate Medical Journal, 94(1113), 374-380.

Barata, I., Shandro, J., Montgomery, M., Polansky, R., Sachs, C., Duber, H., ... Macias-Konstantopoulos, W. (2017). Effectiveness of SBIRT for alcohol use disorders in the emergency department: A systematic review. Western Journal of Emergency Medicine, 18(6), 1143-1152.

Brandsma, L. (2007). Eating disorders across the lifespan. Journal of Women \& Aging, 9(1-2), 155-172. https://doi.org/10.1300/J074v19n01_10

Bush, K., Kivlahan, D. B., McDonell, M. B., Fihn, S. D., \& Bradley, K. A. (1998). The AUDIT alcohol consumption questions (AUDIT-C): An effective brief screening test for problem drinking. Archives of Internal Medicine, 158(16), 1789-1795. https://doi.org/10.1001/archinte.158. 16.1789

Castillo, M., \& Weiselberg, E. (2017). Bulimia nervosa/purging disorder. Current Problems in Pediatric \& Adolescent Health Care, 47(4), 85-94. https://doi.org/10.1016/j.cppeds.2017.02.004

Choo, E. K., McGregor, A. J., Mello, M. J., \& Baird, J. (2013). Gender, violence and brief interventions for alcohol in the emergency department. Drug and Alcohol Dependence, 127, 115-121. https://doi.org/10. 1016/j.drugalcdep.2012.06.021

Cotton, M., Ball, C., \& Robinson, P. (2003). Four simple questions can help screen for eating disorders. Journal of General Internal Medicine, 18(1), 53-56.

Crawford, M., Patton, R., Touquet, R., Drummond, C., Byford, S., Barrett, B., ... Henry, J. (2004). Screening and referral for brief intervention of alcohol misusing patients in an emergency department: A pragmatic randomised controlled trial. Lancet, 364, 1334-1339.

Crow, S., Peterson, C., Swanson, S., Raymond, N., Specker, S., Eckert, E., \& Mitchell, J. (2009). Increased mortality in bulimia nervosa and other eating disorders. The American Journal of Psychiatry, 166(12), 1342-1346.

Crow, S., Praus, B., \& Thuras, P. (1999). Mortality from eating disorders-A 5- to 10-year record linkage study. International Journal of Eating Disorders, 26(1), 97-101. https://doi.org/10.1002/(sici)1098-108x(199907) 26:13.3.co; $2-4$

Cunningham, R. C., Chermack, S. T., Ehrlich, P., Carter, P., Booth, B. M., Blow, F. C., ... Walton, M. A. (2015). Alcohol interventions among underage drinkers in the ED: A randomized controlled trial. Pediatrics, 136(4), 783-793. 
Dawson, D., Smith, S., Saha, T., Rubinsky, A., \& Grant, B. (2012). Comparative performance of the AUDIT-C in screening for DSM-IV and DSM5 alcohol use disorders. Drug \& Alcohol Dependence, 126(3), 384-388.

Deter, H. C., \& Herzog, W. (1994). Anorexia nervosa in a long-term perspective: Results of the Heidelberg-Mannheim study. Psychosomatic Medicine, 56(1), 20-27. https://doi.org/10.1097/00006842-199401000 $-00003$

Dooley-Hash, S., Banker, J. D., Walton, M. A., Ginsburg, Y., \& Cunningham, R. M. (2012). The prevalence and correlates of eating disorders among emergency department patients aged 14-20 years. International Journal of Eating Disorders, 45(7), 883-890. https://doi. org/10.1002/eat.22026

Dooley-Hash, S., Lipson, S., Walton, M. A., \& Cunningham, R. M. (2013). Increased emergency department use by adolescents and young adults with eating disorders. International Journal of Eating Disorders, 46(4), 308-315. https://doi.org/10.1002/eat.22070

Fernandez, A., Waller, R., Walton, M. A., Bonar, E. E., Ignacio, R. V., Chermack, S. T., ... Blow, F. C. (2019). Alcohol use severity and age moderate the effects of brief interventions in an emergency department. Drug and Alcohol Dependence, 194, 386-394.

Forrest, L. N., Smith, A. R., \& Swanson, S. A. (2017). Characteristics of seeking treatment among U.S. adolescents with eating disorders. International Journal of Eating Disorders, 50(7), 826-833. https://doi.org/ 10.1002/eat.22702

Fouladi, F., Mitchell, J. E., Crosby, R. D., Engel, S. G., Crow, S., Hill, L., ... Steffen, K. J. (2015). Prevalence of alcohol and other substance use in patients with eating disorders. European Eating Disorder Review, 23(6), 531-536. https://doi.org/10.1002/erv.2410

Gagne, D. A., Von Holle, A., Brownley, K. A., Runfola, C. D., Hofmeier, S., Branch, K. E., \& Bulik, C. M. (2012). Eating disorder symptoms and weight and shape concerns in a large web-based convenience sample of women ages 50 and above: Results of the gender and body image (GABI) study. International Journal of Eating Disorders, 45(7), 832-844. https://doi.org/10.1002/eat.22030

Guerdjikova, A. I., Mori, N., Casuto, L. S., \& McElroy, S. L. (2017). Binge eating disorder. Psychiatric Clinics of North America, 40(2), 255-266. https://doi.org/10.1016/j.psc.2017.01.003

Harris, E. C., \& Barraclough, B. (1998). Suicide as an outcome for mental disorders. A meta-analysis. The British Journal of Psychiatry, 170(3), 205-228.

Hart, L. M., Granillo, M. T., Jorm, A. F., \& Paxton, S. J. (2011). Unmet need for treatment in the eating disorders: A systematic review of eating disorder specific treatment seeking among community cases. Clinical Psychological Reviews, 31(5), 727-735. https://doi.org/10.1016/j.cpr. 2011.03.004

Hill, L. S., Reid, F., Morgan, J. F., \& Lacey, J. H. (2010). SCOFF, the development of an eating disorder screening questionnaire. International Journal of Eating Disorders, 43(4), 344-351. https://doi.org/10.1002/eat.20679

Hosmer, D. W., \& Lemeshow, S. (2000). Applied logistic regression. Hoboken, NJ: Wiley. https://doi.org/10.1002/0471722146

Hudson, J. I., Hiripi, E., Pope, H. G., \& Kessler, R. C. (2007). The prevalence and correlates of eating disorders in the National Comorbidity Survey Replication. Biological Psychiatry, 61(3), 348-358. https://doi.org/10. 1016/j.biopsych.2006.03.040

IBM Corporation. (2016). IBM SPSS statistics for windows, version 24.0. Armonk, NY: IBM Corp.

Johnston, O., Fornai, G., Cabrini, S., \& Kendrick, T. (2007). Feasibility and acceptability of screening for eating disorders in primary care. Family Practice, 24(5), 511-517. https://doi.org/10.1093/fampra/cmm029

Killeen, T. K., Greenfield, S. F., Bride, B. E., Cohen, L., Gordon, S. M., \& Roman, P. M. (2011). Assessment and treatment of co-occurring eating disorders in privately funded addiction treatment programs. The American Journal on Addictions, 20(3), 205-211. https://doi.org/10.1111/j. 1521-0391.2011.00122.x

Krug, I., Treasure, J., Anderluh, M., Bellodi, L., Cellini, E., di Bernardo, M., ... Fernández-Aranda, F. (2008). Present and lifetime comorbidity of tobacco, alcohol and drug use in eating disorders: A European multicenter study. Drug and Alcohol Dependence, 97, 169-179. https://doi. org/10.1111/j.1440-1819.2008.01908.x

Le Grange, D., \& Loeb, K. L. (2007). Early identification and treatment of eating disorders: Prodrome to syndrome. Early Intervention in Psychiatry, 1(1), 27-39. https://doi.org/10.1111/j.1751-7893.2007.00007.x

Luck, A. J., Morgan, J., Reid, F., O'Brien, A., Brunton, J., \& Price, C. (2002). The SCOFF questionnaire and clinical interview for eating disorders in general practice: Comparative study. British Medical Journal, 325 (7367), 755-756. https://doi.org/10.1136/bmj.325.7367.755

Maine, M., Samuels, K., \& Tantillo, M. (2015). Eating disorders in adult women: Biopsychosocial, developmental and clinical considerations. Advances in Eating Disorders: Research and Practice, 3, 1-11.

Mangweth-Matzek, B., Hoek, H. W., \& Pope, H. G., Jr. (2014). Pathological eating and body dissatisfaction in middle-aged and older women. Current Opinion in Psychiatry, 27(6), 431-435. https://doi.org/10.1097/ YCO.0000000000000102

Mangweth-Matzek, B., Hoek, H. W., Rupp, C. I., Lackner-Seifert, K., Frey, N., Whitworth, A. B., ... Kinz, L. J. (2014). Prevalence of eating disorders in middle-aged women. International Journal of Eating Disorders, 47(3), 320-324. https://doi.org/10.1002/eat.22232

Micali, N., Martini, M. G., Thomas, J. J., Eddy, K. T., Kothari, R., Russell, E., ... Treasure, J. (2017). Lifetime and 12-month prevalence of eating disorders amongst women in mid-life: A population-based study of diagnoses and risk factors. BMC Medicine, 15, 12. https://doi.org/10. 1186/s12916-016-0766-4

Miller, I., Camargo, C., Arias, S., Sullivan, A., Allen, M., Goldstein, A., ... for the ED-SAFE Investigators. (2017). Suicide prevention in an emergency department population the ED-SAFE study. JAMA Psychiatry, 74(6), 563-570. https://doi.org/10.1001/jamapsychiatry.2017. 0678

Mond, J. M., Myers, T. C., Crosby, R. D., Hay, P. J., Rodgers, B., Morgan, J. F., ... Mitchell, J. E. (2008). Screening for eating disorders in primary care: EDE-Q versus SCOFF. Behaviour Research and Therapy, 46(5), 612-622. https://doi.org/10.1016/j.brat.2008.02.003

Morgan, J. F., Reid, F., \& Lacey, J. H. (1999). The SCOFF questionnaire: Assessment of a new screening tool for eating disorders. British Medical Journal, 319(7223), 1467-1468.

Moskowitz, L., \& Weiselberg, E. (2017). Anorexia nervosa/atypical anorexia nervosa. Current Problems in Pediatric \& Adolescent Health Care, 47(4), 70-84. https://doi.org/10.1016/j.cppeds.2017.02.003

Ogg, E. C., Millar, H. R., Pusztai, E. E., \& Thom, A. S. (1997). General practice consultation patterns preceding diagnosis of eating disorders. International Journal of Eating Disorders, 22(1), 89-93.

Pike, K. M., Dunne, P. E., \& Addai, E. (2013). Expanding the boundaries: Reconfiguring the demographics of the "typical" eating disordered patient. Current Psychiatry Reports, 15(11), 411.

Pike, K. M., Hoek, H. W., \& Dunne, P. E. (2014). Cultural trends and eating disorders. Current Opinion in Psychiatry, 27(6), 436-442. https://doi. org/10.1007/s11920-013-0411-2

Pringle, J., Kelley, D., Kearney, S., Aldridge, A., Dowd, W., Johnjulio, W., ... Lovelace, J. (2018). Screening, brief intervention, and referral to treatment in the emergency department: An examination of health care utilization and costs. Medical Care, 56(2), 146-152.

Ratnasuriya, R. H., Eisler, I., Szmukler, G. I., \& Russell, G. F. (1991). Anorexia nervosa: Outcome and prognostic factors after 20 years. British Journal of Psychiatry, 158(4), 495-502. https://doi.org/10. 1192/bjp.158.4.495

Seah, X., Tham, X., Kamaruzaman, N., \& Yobas, P. (2017). Knowledge, attitudes and challenges of healthcare professionals managing people with eating disorders: A literature review. Archives of Psychiatric Nursing, 31, 125-136.

Spitzer, R. L., Kroenke, K., \& Williams, J. (1999). Validation and utility of a self-report version of PRIME-MD; the PHQ primary care study. Journal of the American Medical Association, 282(18), 1737-1744. 
Striegel-Moore, R. H., Dohm, F. A., Kraemer, H. C., Schreiber, G. B., Crawford, P. B., \& Daniels, S. R. (2005). Health services use in women with a history of bulimia nervosa or binge eating disorder. International Journal of Eating Disorder, 37(1), 11-18.

Swanson, S. A., Crow, S. J., Le Grange, D., Swendsen, J., \& Merikangas, K. R. (2011). Prevalence and correlates of eating disorders in adolescents: Results from the National Comorbidity Survey Replication Adolescent Supplement. Archives of General Psychiatry, 68(7), 714-723. http://doi.org/10.1001/archgenpsychiatry.2011.22

Treasure, J., \& Russell, G. (2011). The case for early intervention in anorexia nervosa: Theoretical exploration of maintaining factors. British Journal of Psychiatry, 199(1), 5-7. https://doi.org/10.1192/bjp.bp. 110.087585

United States Census Bureau-a. (2018). Retrieved from https://factfinder. census.gov/faces/tableservices/jsf/pages/productview.xhtml?src=CF

United States Census Bureau-b. (2018). Retrieved from https://factfinder. census.gov/faces/tableservices/jsf/pages/productview.xhtml?src=CF

United States Census Bureau-c. (2018). Retrieved from https://factfinder. census.gov/faces/tableservices/jsf/pages/productview.xhtml?src=CF
Weltzin, T. E., Cornella-Carlson, T., Fitzpatrick, M. E., Kennington, B., Bean, P., \& Jefferies, C. (2012). Treatment issues and outcomes for men with eating disorders. Eating Disorders, 20(5), 444-459. https:// doi.org/10.1080/10640266.2012.715527

WHO. (1995). Physical status: The use and interpretation of anthropometry. Geneva, Switzerland: The World Health Organization.

WHO ASSIST Working Group. (2002). The alcohol, smoking, and substance involvement screening test, ASSIST: Development reliability and feasibility. Addiction, 97, 1183-1194.

How to cite this article: Dooley-Hash S, Adams M, Walton MA, Blow FC, Cunningham RM. The prevalence and correlates of eating disorders in adult emergency department patients. Int J Eat Disord. 2019;52:1281-1290. https://doi. org/10.1002/eat.23140 